\title{
Malaria in the Time of COVID-19: Do Not Miss the Real Cause of Illness
}

\author{
Johannes Jochum ${ }^{1, *(\mathbb{D}}$, Benno Kreuels ${ }^{1}$, Egbert Tannich ${ }^{2}{ }^{(0)}$, Samuel Huber ${ }^{3}$, Julian Schulze zur Wiesch ${ }^{3}{ }^{(0)}$, \\ Stefan Schmiedel ${ }^{3}$, Michael Ramharter ${ }^{1}$ (1) and Marylyn M. Addo ${ }^{3}(1)$
}

1 Department of Tropical Medicine, Bernhard Nocht Institute for Tropical Medicine \& I. Department of Medicine, University Medical Center Hamburg-Eppendorf, 20359 Hamburg, Germany; b.kreuels@uke.de (B.K.); ramharter@bnitm.de (M.R.)

2 National Reference Centre for Tropical Pathogens, Bernhard Nocht Institute for Tropical Medicine, 20359 Hamburg, Germany; tannich@bnitm.de

3 I. Department of Medicine, University Medical Center Hamburg-Eppendorf, 20246 Hamburg, Germany; s.huber@uke.de (S.H.); j.schulze-zur-wiesch@uke.de (J.S.z.W.); s.schmiedel@uke.de (S.S.); m.addo@uke.de (M.M.A.)

* Correspondence: j.jochum@uke.de; Tel.: +49-40428180

Citation: Jochum, J.; Kreuels, B.; Tannich, E.; Huber, S.; Schulze zur Wiesch, J.; Schmiedel, S.; Ramharter, M.; Addo, M.M. Malaria in the Time of COVID-19: Do Not Miss the Real Cause of Illness. Trop. Med. Infect. Dis. 2021, 6, 40. https://doi.org/10.3390/ tropicalmed6020040

Academic Editor: Peter A. Leggat

Received: 8 March 2021

Accepted: 22 March 2021

Published: 26 March 2021

Publisher's Note: MDPI stays neutral with regard to jurisdictional claims in published maps and institutional affiliations.

Copyright: (c) 2021 by the authors. Licensee MDPI, Basel, Switzerland. This article is an open access article distributed under the terms and conditions of the Creative Commons Attribution (CC BY) license (https:// creativecommons.org/licenses/by/ $4.0 /)$.

\begin{abstract}
We report a case of Plasmodium falciparum malaria in a patient asymptomatically coinfected with severe acute respiratory syndrome coronavirus 2 (SARS-CoV-2). In the current ongoing coronavirus pandemic, co-infections with unrelated life-threatening febrile conditions may pose a particular challenge to clinicians. The current situation increases the risk for cognitive biases in medical management.
\end{abstract}

Keywords: severe acute respiratory syndrome coronavirus 2; plasmodium falciparum; differential diagnosis; cognitive bias; diagnostic reasoning

Since the end of 2019, the global outbreak of coronavirus disease 2019 (COVID-19) has spread rapidly and represents a major challenge to many healthcare systems worldwide [1]. In this situation, co-infections and comorbidities pose a particular challenge to clinicians, as the current focus on COVID-19 management may, on the one hand, lead to inappropriate diagnostics and management of other medical conditions, and on the other hand, to the risk of propagation of severe acute respiratory syndrome coronavirus 2 (SARS-CoV-2) within hospitals. Here, we describe a case of acute falciparum malaria and concurrent SARS-CoV-2 infection, illustrating the challenges in diagnostic reasoning during the current pandemic.

A 61-year-old female patient presented at the emergency department of the University Medical Center Hamburg-Eppendorf on 22 March 2020 with a fever of $40.2{ }^{\circ} \mathrm{C}$, myalgia, and diarrhea. All symptoms had been present for four days. Nine days before presentation, she had returned from a two-week journey to Cameroon. She reported no chronic medical conditions or regular medication. Due to her recent air travel, fever and the ongoing pandemic with COVID-19, she was tested for SARS-CoV-2. Reverse transcription PCR of an oropharyngeal swab turned out positive and the patient was admitted to the COVID19 isolation ward. Auscultation, lung ultrasound, and chest X-ray revealed no findings consistent with an atypical pneumonia (Figure 1). Laboratory results showed severe thrombocytopenia of 23,000/ $\mathrm{LL}$ and C-reactive protein of $103 \mathrm{mg} / \mathrm{L}$ (Table 1 ). These results were considered atypical for a clinically mild case of COVID-19, given the available data [2] Therefore, differential diagnoses were sought.

Prior to admission, the patient herself had already initiated presumptive treatment for malaria with atovaquone-proguanil due to her recent travel and lack of chemoprophylaxis. As history and laboratory findings were, indeed, compatible with malaria, we performed a microscopic examination of the patient's blood. A thin blood film was found to be positive for Plasmodium falciparum with an asexual parasitemia of $4 \%$ (Figure 2). Treatment with 
atovaquone-proguanil was continued and all clinical symptoms subsided on day three after admission. Two sets of blood cultures and PCR diagnostic for influenza remained negative. Although the detection of SARS-CoV-2 was confirmed in a subsequent sample, the patient never experienced respiratory symptoms during the follow-up of one month.

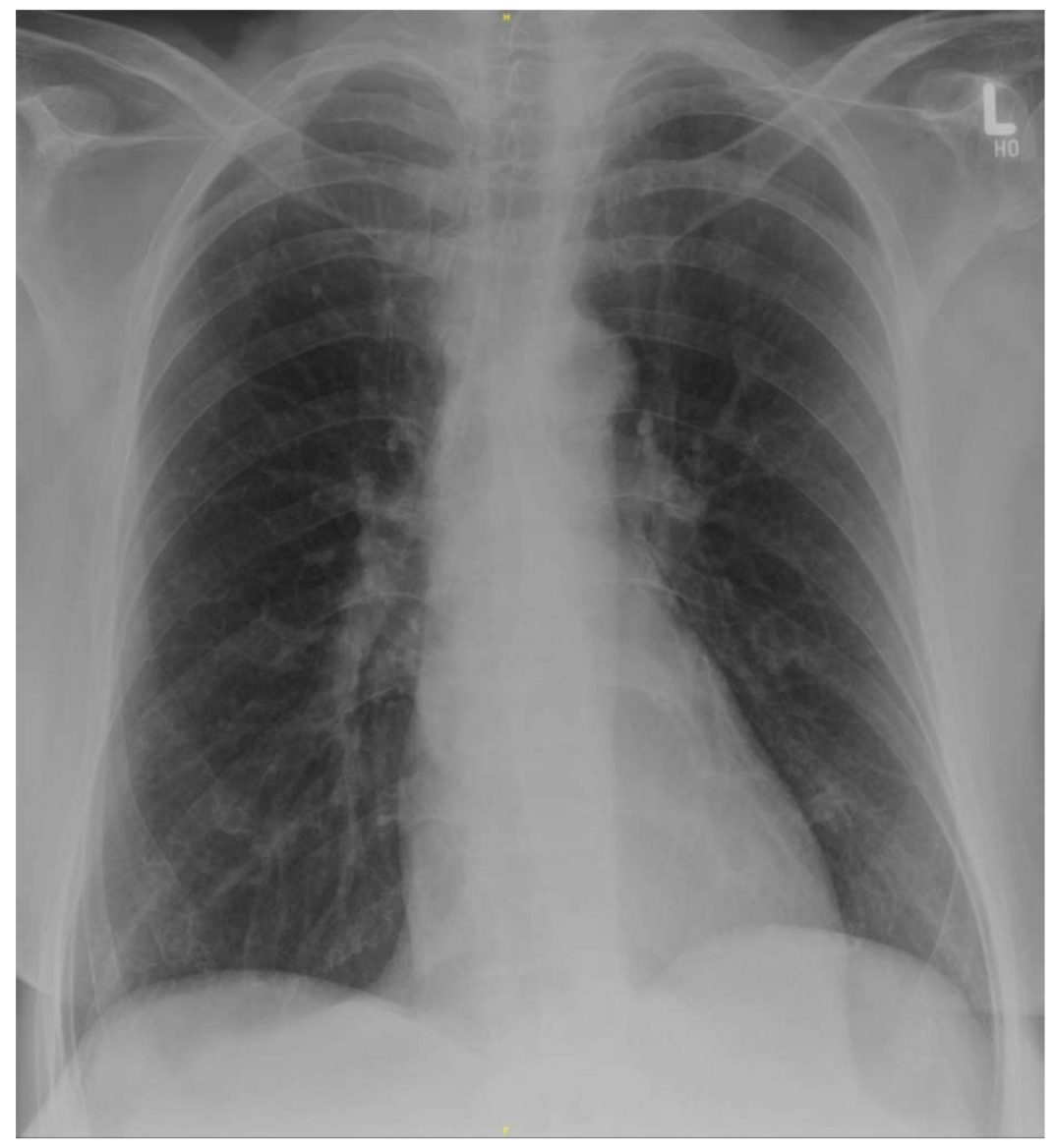

Figure 1. Supine chest $X$-ray at the time of admission without evidence of pneumonic consolidations or ground glass opacities. Courtesy of Prof. Gerhard Adam, Department of Diagnostic and Interventional Radiology and Nuclear Medicine, University Medical Center Hamburg-Eppendorf, Hamburg.

Table 1. Laboratory values of the patient on admission, 4 days after onset of symptoms.

\begin{tabular}{ccc}
\hline Laboratory Parameter and Unit & Patient Value & Reference Range \\
\hline Leucocyte count/ $\mu \mathrm{L}$ & 2700 & $3800-11,000$ \\
Hemoglobin $\mathrm{g} / \mathrm{dL}$ & 13.9 & $12.3-15.3$ \\
Platelet count/ $\mu \mathrm{L}$ & 23,000 & $150,000-400,000$ \\
Total bilirubin $\mathrm{mg} / \mathrm{dL}$ & 1.5 & $0.3-1.2$ \\
Alanine aminotransferase U/L & 40 & $<35$ \\
Aspartate aminotransferase U/L & 36 & $<35$ \\
Lactate dehydrogenase U/L & 358 & $120-246$ \\
Creatinine mg/dL & 0.67 & $0.55-1.02$ \\
C-reactive protein $\mathrm{mg} / \mathrm{L}$ & 103 & $<5$ \\
\hline
\end{tabular}

Due to its increasingly wide spread distribution in the population, COVID-19 may be encountered as a co-infection with any other classical disease. Dual infection with SARS-CoV-2 and malaria have been reported recently, with most patients being free of respiratory symptoms attributable to SARS-CoV-2 [3,4]. It is of importance not to miss such co-infections to avoid in-hospital spread of SARS-CoV-2 infection with the potential for high mortality in other hospitalized patients. At the same time, it is important not to 
narrow the spectrum of differential diagnoses of febrile conditions despite the ongoing COVID-19 pandemic. When patient load is high and staff are in short supply, it is tempting to be satisfied with an initial diagnosis, particularly when this diagnosis is consistent with the current outbreak. The pandemic situation contributes to the risk for cognitive biases during the medical management, in particular, availability bias and premature closure $[5,6]$.

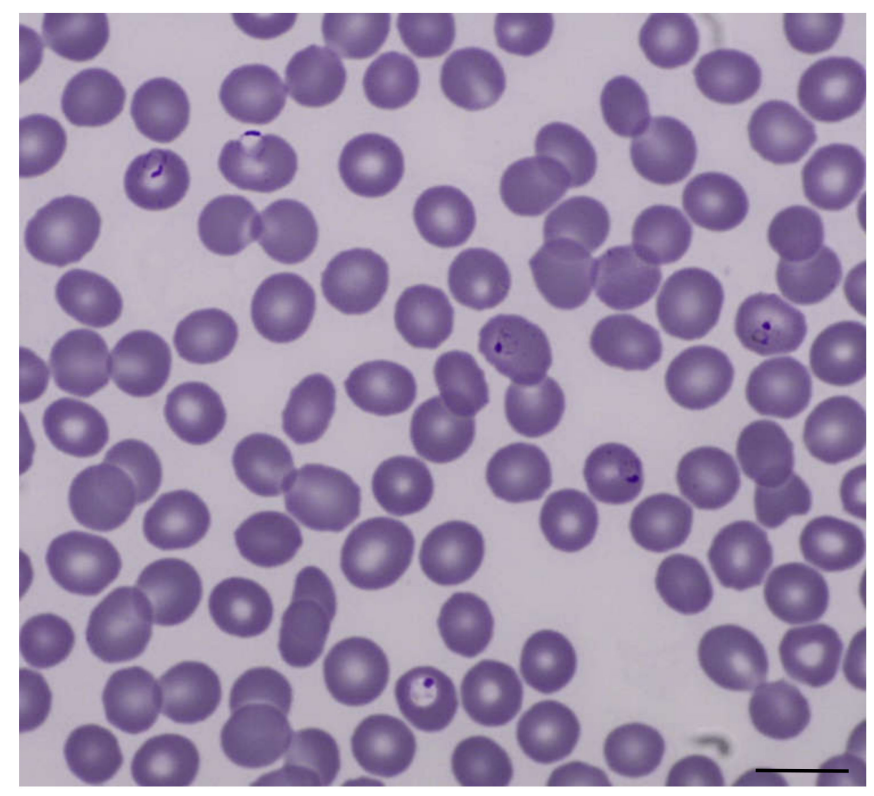

Figure 2. Thin blood film with Plasmodium falciparum trophozoites, Giemsa stain, original magnification $1000 \times$. Scale bar: $10 \mu \mathrm{m}$

Importantly, only one day after admission of our patient, we received a telephone call by a desperate man who was denied a medical evaluation when he developed a high fever after travel to Ghana. His family doctor, as well as the local hospital, judged this to likely be COVID-19 and recommended home isolation-advice that has potentially fatal consequences. Subsequently, this patient was also admitted to hospital with Plasmodium falciparum malaria. The two patients illustrate the currently increased risk of missing life-threatening differential diagnoses with the requirement of a specific therapy beyond giving antibiotics for suspected sepsis. This becomes even more relevant when international travel is relaunched and is an important lesson for future outbreaks.

Author Contributions: Conceptualization, J.J., M.R., and M.M.A.; writing-original draft preparation, J.J. writing—review and editing, J.J., B.K., E.T., S.H., J.S.z.W., S.S., M.R. and M.M.A.; supervision, M.R. and M.M.A. All authors have read and agreed to the published version of the manuscript.

Funding: This research received no external funding.

Institutional Review Board Statement: Not applicable.

Informed Consent Statement: Obtained.

Data Availability Statement: Not applicable.

Acknowledgments: We thank Gerhard Adam, Department of Diagnostic and Interventional Radiology and Nuclear Medicine, University Medical Center Hamburg-Eppendorf, Hamburg, for providing the chest $X$-ray image of the patient.

Conflicts of Interest: The authors declare no potential conflict of interest. 


\section{References}

1. World Health Organization. Coronavirus Disease 2019 (COVID-19) Epidemiological Update 28.09.2020. Available online: https: / / www.who.int/docs / default-source/coronaviruse/situation-reports / 20200928-weekly-epi-update.pdf?sfvrsn=9e354665_4 (accessed on 29 September 2020).

2. Guan, W.J.; Ni, Z.Y.; Hu, Y.; Liang, W.H.; Ou, C.Q.; He, J.X.; Zhong, N.S. Clinical characteristics of Coronavirus disease 2019 in China. N. Engl. J. Med. 2020, 382, 1708-1720. [CrossRef] [PubMed]

3. Sardar, S.; Sharma, R.; Alyamani, T.Y.M.; Aboukamar, M. COVID-19 and Plasmodium vivax malaria co-infection. IDCases 2020 21, e00879. [CrossRef]

4. Correia, M.J.; Frade, L.; Guerreiro, R.; Araujo, I.; Baptista, T.; Fonseca, C.; Mansinho, K. A patient with severe malaria and COVID-19: How do you tell the difference between these infections? Eur. J. Case Rep. Intern. Med. 2020, 7, 002007. [CrossRef] [PubMed]

5. Saposnik, G.; Redelmeier, D.; Ruff, C.C.; Tobler, P.N. Cognitive biases associated with medical decisions: A systematic review. BMC Med. Inform. Decis. Mak. 2016, 16, 138. [CrossRef] [PubMed]

6. Norman, G.R.; Monteiro, S.D.; Sherbino, J.; Ilgen, J.S.; Schmidt, H.G.; Mamede, S. The causes of errors in clinical reasoning: Cognitive biases, knowledge deficits, and dual process thinking. Acad. Med. 2017, 92, 23-30. [CrossRef] [PubMed] 